This item was submitted to Loughborough's Research Repository by the author.

Items in Figshare are protected by copyright, with all rights reserved, unless otherwise indicated.

\title{
The performance and durability of single-layer sol-gel anti-reflection coatings applied to solar module cover glass
}

PLEASE CITE THE PUBLISHED VERSION

https://doi.org/10.1016/j.surfcoat.2018.11.030

PUBLISHER

Elsevier

VERSION

VoR (Version of Record)

PUBLISHER STATEMENT

This work is made available according to the conditions of the Creative Commons Attribution 4.0 International (CC BY 4.0) licence. Full details of this licence are available at: http://creativecommons.org/licenses/ by/4.0/

\section{LICENCE}

CC BY 4.0

\section{REPOSITORY RECORD}

Womack, Gerald, Kenan Isbilir, Fabiana Lisco, Geraldine Durand, Alan Taylor, and Michael Walls. 2019. "The Performance and Durability of Single-layer Sol-gel Anti-reflection Coatings Applied to Solar Module Cover Glass". figshare. https://hdl.handle.net/2134/36109. 


\title{
The performance and durability of single-layer sol-gel anti-reflection coatings applied to solar module cover glass
}

\author{
Gerald Womack $^{\mathrm{a}, *}$, Kenan Isbilir ${ }^{\mathrm{a}}$, Fabiana Lisco ${ }^{\mathrm{a}}$, Geraldine Durand ${ }^{\mathrm{b}}$, Alan Taylor ${ }^{\mathrm{b}}$, \\ John M. Walls ${ }^{\mathrm{a}}$ \\ ${ }^{\text {a }}$ CREST (Centre for Renewable Energy Systems and Technology), The Wolfson School of Mechanical, Electrical and Manufacturing Engineering, Loughborough University, \\ Loughborough LE11 3TU, United Kingdom \\ ${ }^{\mathrm{b}}$ TWI Ltd, Granta Park, Great Abington, Cambridge CB21 6AL, United Kingdom
}

\section{A R T I C L E I N F O}

\section{Keywords:}

Anti-reflection

Coating

Solution-gelation

Hard coat

Dip-coated

\begin{abstract}
A B S T R A C T
A significant source of energy loss in photovoltaic (PV) modules is caused by reflection from the front cover glass surface. Reflection from the cover glass causes a loss of $\sim 4 \%$ at the air-glass interface. Only a single air-glass interface can be coated on crystalline silicon solar modules as an ethylene-vinyl acetate (EVA) layer is inserted between the cover glass and the silicon absorber. A single-layer anti-reflection coating (ARC) on the outer surface of the cover glass is effective at reducing reflection losses over the wavelength range of most PV devices. The coating investigated in this work reduces the reflectance loss at the glass surface by $74 \%$. However, the longterm durability of sol-gel coatings has not been established particularly for use in hot and humid climates. In this work, we investigate the damage resistance of a single-layer closed-surface hard coat ARC, deposited using solgel methods by applying a variety of accelerated weathering, scratch and abrasion test methods.

The reflectance of the sol-gel ARC was measured and then the coating was put through a series of durability and environmental tests. The coating is resistant to damage from heating and can withstand temperatures higher than the phase change temperature of soda-lime glass. Scratch testing demonstrated that the sol-gel AR is relatively hard and difficult to remove from the substrate surface. Pull tests and cross-hatch testing also confirmed the strong adhesion of the coating. Weathering experiments show some degradation in weighted average reflectance, particularly an increase in reflectance of $0.6-0.9 \%$ after $1000 \mathrm{~h}$ of exposure to damp heat. Testing also showed a vulnerability to exposure to acid. These results indicate that the performance of this type of ARC could deteriorate and possibly delaminate in humid climate conditions The ARC had a low water contact angle, which means the coatings are hydrophilic and, therefore, hygroscopic increasing the risk of water damage over extended periods of time. This work shows that sol-gel anti-reflection coatings are currently unsuitable for use on PV and are unlikely to remain durable across the 25 year industry standard.
\end{abstract}

\section{Introduction}

Single-layer anti-reflection coatings (ARCs) are used to reduce reflection losses from the surface of the cover glass of crystalline silicon photovoltaic (PV) modules. They are also applied to cover glass on substrate configuration thin film modules such as CIGS, and directly to the glass superstrate for thin film cadmium telluride (CdTe) modules. Mainstream technology solar panels are provided with a 25 year warranty, so ARCs for solar modules must be durable on a time-scale matching this industry standard. Solar modules undergo a series of accelerated environmental and durability standard tests to ensure they can withstand decades of outdoor exposure, in accordance with the
International Electrotechnical commission (IEC) standards [1]. As ARCs will undergo the same stresses and weathering as the solar panel, IEC module standards should also be applied to ARCs designed for application on solar modules. Coatings on cover glass are continuously exposed to the environment, and additional testing protocols must ensure that all possible mechanisms resulting in degradation are simulated by the testing protocols.

There are different types of ARC available. The choice of coating is governed by considerations of performance, durability, ease of application, and cost. At present, the industry is predominantly using lowcost single-layer sol-gel coatings, which are deposited in atmospheric conditions using solution processing techniques. These coatings provide

\footnotetext{
* Corresponding author.

E-mail address: g.womack@lboro.ac.uk (G. Womack).
} 
effective anti-reflection performance with assurances of the longevity of the coating, such as no visual degradation after $1000 \mathrm{~h}$ of damp heat exposure and resistance to $60 \mathrm{~h}$ of exposure to sulfuric and nitric acid $[2,3]$.

Porous sol-gel coatings are known to be mechanically fragile and vulnerable to water ingress and contamination, which affects the refractive index and, therefore, the transmissivity and reflectivity of the ARC $[4,5]$. It is possible to improve the vulnerability to water damage of sol-gel coatings. However, there is a trade-off between the optical properties of the coating, hydrophobicity, and resistance to mechanical damage. Sol-gel ARCs currently in use are predominantly hydrophilic hard coatings with a non-porous closed top surface [2], which are more resistant to water damage than traditional porous silica coatings. Solgel hard coatings have shown increased resistance to damp heat exposure, when compared to porous sol-gel ARCs [2]. In this work, we report on the results of extensive tests to evaluate the performance and durability of a closed surface sol-gel hard coat.

A variety of assessment tests should be performed to test the durability of sol-gel anti-reflective surface coatings [6]. The scratch resistance of the ARC was measured using micro-indentation scratch tests [7]. Pull test and crosshatch tests have also been used to evaluate the adhesion of the coating on the substrate surface. In the case of thin film solar cell technologies using a superstrate configuration, it may be attractive for an ARC to be on the surface of the glass before the cell is deposited on the other side, simplifying the manufacturing process. This necessitates resistance to the high temperatures (up to $500^{\circ} \mathrm{C}$ ) involved in the thin film photovoltaic stack deposition [8]. By performing standard tests, such as damp heat, temperature cycling [9], and acid exposure [10], resistance to weathering damage has been assessed. The water contact angle of the coatings has also been measured, giving insight into the hydrophobicity/hydrophilicity of the coating. New multi-variate analysis methods are being developed to enable an effective and meaningful comparison between different coatings and surface treatment methods [11]. A coating is considered durable and fit for purpose once it has passed all tests.

For comparison, high performance broadband multilayer ARCs (MAR), deposited using high vacuum PVD techniques, are an alternative to sol-gel coatings [12]. The results of applying this battery of environmental and durability tests to MARs has been reported [13].

\section{Sol-gel single-layer coating design}

\subsection{Single-layer anti-reflection}

The ideal refractive index of a coating for maximum transmission was first derived by Lord Rayleigh [14]. The refractive index of an optimized single-layer ARC, with clearly defined step changes in refractive index, is defined in Eq. (1)

$n_{c}=\sqrt{n_{1} n_{2}}$

where $n_{c}$ is the refractive index of the coating, $\mathrm{n}_{1}$ is the refractive index of the entrance medium, and $n_{2}$ is the refractive index of the exit medium. In the case of an air-glass interface, assuming the refractive index of glass is $\sim 1.5$ at a wavelength of $550 \mathrm{~nm}$, the ideal refractive index for a single-layer ARC is $\sim 1.22$. By manipulating the ratio between silica and voids within a coating, a refractive index as low as 1.22 is achievable through sol-gel deposition.

Single-layer anti-reflection is also achieved through the manipulation of reflections from different layer interfaces to create destructive interference, between the glass-coating interface and the coating-air interface. As shown in Fig. 1, the ideal thickness of interference based single-layer coatings is a quarter the wavelength of incident light. As the thickness of a coating can only be a quarter length of a single wavelength, the effectiveness of single-layer ARC is maximised at a single wavelength. Additionally, as the path length through the single-layer ARC depends on the path taken through the coating, destructive

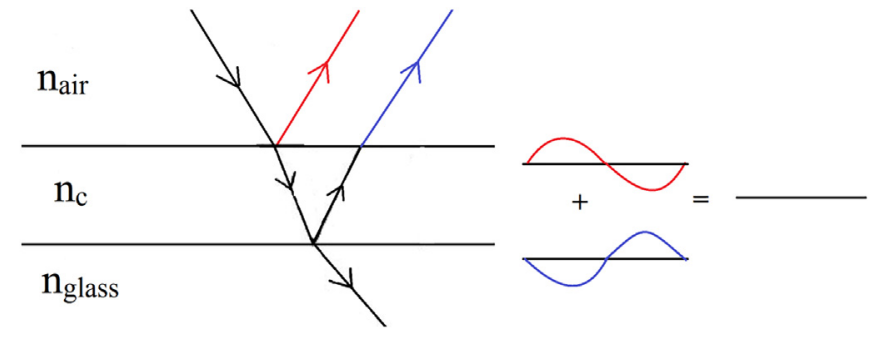

Fig. 1. The anti-reflection effect of a single-layer ARC, reflected light from two interfaces cause destructive interference.

interference is most effective at a single angle of incidence.

\subsection{Chemistry and deposition method}

Although magnesium fluoride has a lower refractive index than $\mathrm{SiO}_{2}$ (At $550 \mathrm{~nm}$, the refractive index is $\sim 1.38$ for $\mathrm{MgF}_{2}$ and $\sim 1.46$ for $\mathrm{SiO}_{2}$ ), $\mathrm{SiO}_{2}$ is readily available, abundant. Silica $\left(\mathrm{SiO}_{2}\right)$ is the most common material used in single-layer AR coatings deposited through the sol-gel method. The refractive index of the material lowers as the void percentage (air pockets within the film) increases. As the porosity of the coating increases, the friability of the coating increases. The refractive index of deposited coatings has been reported to be as low as $\mathrm{n}=1.15$ [15].

It is possible to control the parameters of sol-gel deposition, such as dip speed, solution viscosity, and spin rates to obtain greater control over the dimensions of microstructures in sol-gel surfaces, such as surface area and thickness, void radius, and volume [16,17]. Thickness control in sol-gel deposition is fairly good as deposition parameters can be manipulated and refined to give the desired thickness. The thickness of sol-gel deposited films ranges from 50 to $500 \mathrm{~nm}$ [18]. The refractive index of the sol-gel coatings tested in this work was measured by spectroscopic ellipsometry to be sub optimal, slightly over 1.26 in the range of $407 \mathrm{~nm}$ to $433 \mathrm{~nm}$. However the refractive index outside of this range was between 1.28 and 1.29 across most of the spectrum, as can be seen in Fig. 2.

Most sol-gel materials used for ARC coatings use alkoxysilanes as the precursors, to grow silica particulates (Stöber Spheres) or to bind together pre-existing silica particulates. A range of alkoxysilanes has been used, including high silica content systems [19]. Some patents also describe use of the commercially available colloidal silica, or use of hollow ceramic spheres [20,21].

The coating investigated in this work is broadly based on the technology described by Thies [22].

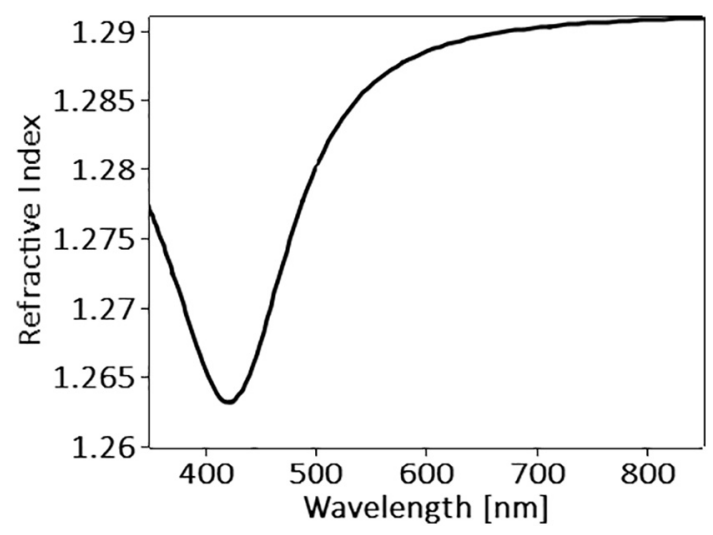

Fig. 2. Measured refractive index of the sol-gel coating. 


\section{Sol-gel anti-reflection optical performance and imaging}

The optical performance of single-layer coatings depends on the refractive index and thickness of the coating. To maintain anti-reflective performance for solar modules across wide wavelength ranges, an ARC must have a reflection minimum at the most energy dense region of the solar spectrum. The AM1.5 spectrum is heavily weighted in the $350 \mathrm{~nm}$ to $650 \mathrm{~nm}$ wavelength range. Consequently, it is reasonable to use a coating designed for use in the visible light wavelengths across broader wavelength ranges, as long as the coating remains transparent across the broader wavelength range. The ARC investigated in this work does not absorb in the $350 \mathrm{~nm}-1100 \mathrm{~nm}$ wavelength range. This means the coating is optically suitable for most solar cell technologies of varying bandgaps, including crystalline silicon and CIGS, with a bandgap of $\sim 1.13 \mathrm{eV}(350 \mathrm{~nm}-\sim 1100 \mathrm{~nm})$, and CdTe with a bandgap of $\sim 1.46 \mathrm{eV}(350 \mathrm{~nm}-\sim 850 \mathrm{~nm})$. Glass begins to absorb light heavily between $350 \mathrm{~nm}-400 \mathrm{~nm}$. The performance of the coating was measured for different PV technologies by calculating the weighted average reflectance (WAR) of the coating across different wavelength ranges. WAR is an average reflectance across a given wavelength range, wavelengths are weighted by the relative abundance of photons at each wavelength in the AM1.5 solar spectrum. Calculating the WAR allows reflectance to be easily compared between different coatings. The measured reflection from the ARC coated glass compared to uncoated glass is shown in Fig. 3.

The reflectance of the sol-gel ARC was measured using a Varian Cary 5000 UV-vis-IR spectrophotometer. Reflectance from both sides of the glass samples was obtained to allow comparison of the reflectance of the coating to that of uncoated glass, with no manipulation of the data. Across the CdTe wavelength range $(350 \mathrm{~nm}, 850 \mathrm{~nm})$, the WAR from a $3 \mathrm{~mm}$ soda-lime glass slide, coated on both sides with sol-gel ARC, is reduced to $2.2 \%$ across 2 interfaces, from $8.72 \%$ on bare glass. To maintain consistency all results presented in this work consider both interfaces of the samples. When employed on a module, the coating is deposited only on outer side of the glass with the PV cell on the other. Across the crystalline silicon/CIGS wavelength range $(350 \mathrm{~nm}$, $1100 \mathrm{~nm}$ ), the WAR is reduced to $2.7 \%$ from $8.62 \%$.

A comparison of the effectiveness of the ARC across different PV technology wavelength ranges is shown in Table 1 . The results show that because the AM1.5 solar spectrum is heavily weighted in the visible light region of the electro-magnetic spectrum, extending the wavelength range has a limited effect on the overall optical performance of the coating.

An SEM image of a cross-section through the ARC on glass is shown

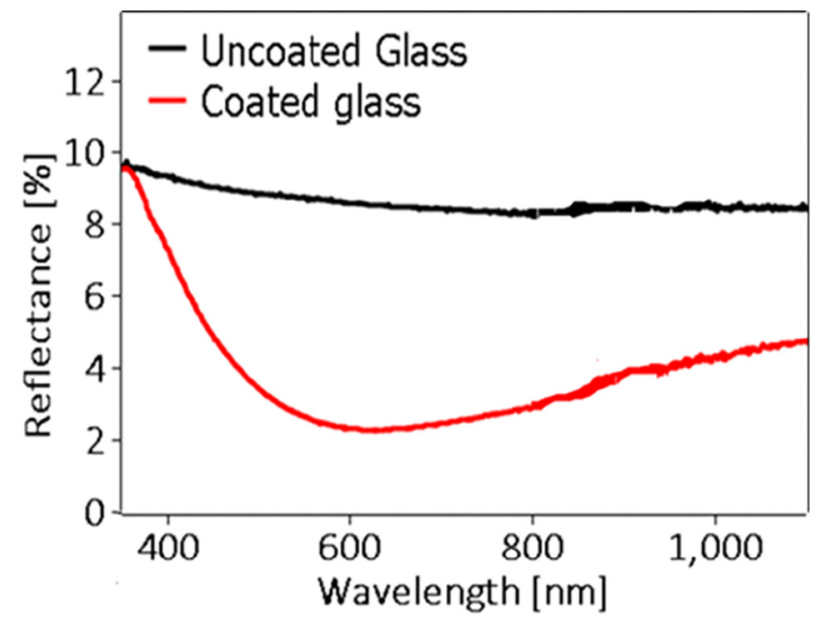

Fig. 3. The measured reflectance from both back and front surfaces of an uncoated glass sample and an ARC coated sample coated on both sides, between $350 \mathrm{~nm}$ and $1100 \mathrm{~nm}$.
Table 1

A comparison of coating reflectance across the wavelength ranges of different PV technologies.

\begin{tabular}{lll}
\hline & $\begin{array}{l}\text { Sol-gel ARC } \\
\text { WAR [\%] }\end{array}$ & $\begin{array}{l}\text { Reflectance percentage reduction } \\
\text { sol-gel ARC [\%] }\end{array}$ \\
\hline CdTe & 2.2 & 74 \\
Crystalline silicon/CIGS & 2.7 & 69 \\
\hline
\end{tabular}

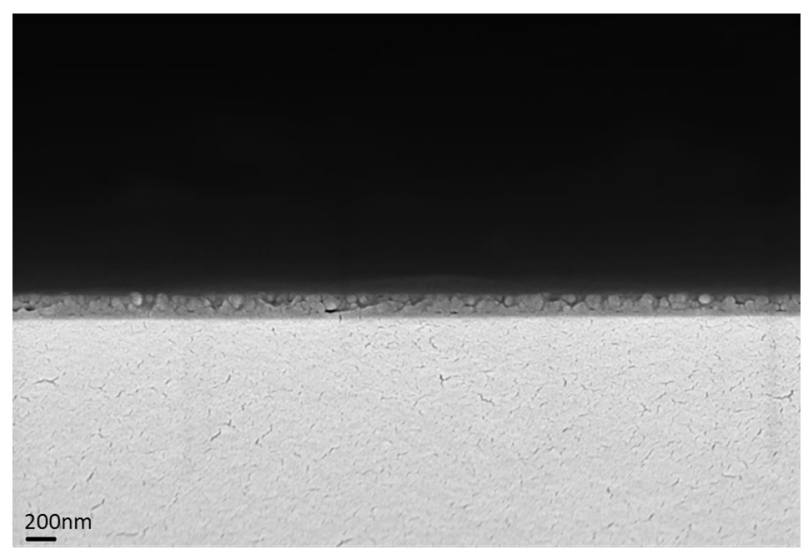

Fig. 4. An SEM image of a cross section of the ARC on a soda-lime glass substrate.

in Fig. 4. The coating thickness is $\sim 180 \mathrm{~nm}$ with little variation in thickness visible in the image. To achieve minimal reflectance, a coating with this refractive index dispersion (1.26-1.29) would be $\sim 100 \mathrm{~nm}$ thick. Therefore, the coating thickness is not optically optimal. It has been shown that similar sol-gel coatings, $1 / 4$ wavelength thick, reduce reflectance to $<0.5 \%$ [23]. The surface is mostly closed, but some defects that may make the coating susceptible to water damage are apparent. A close up of a defect is shown in Fig. 5.

\section{Durability of the sol-gel coatings}

\subsection{Adhesion}

Adhesion is an important measure of coating durability, as low adhesion implies the coating is easy to remove from the substrate surface. Adhesion of the sol-gel coating was measured using the pull test and the cross hatch test methods.

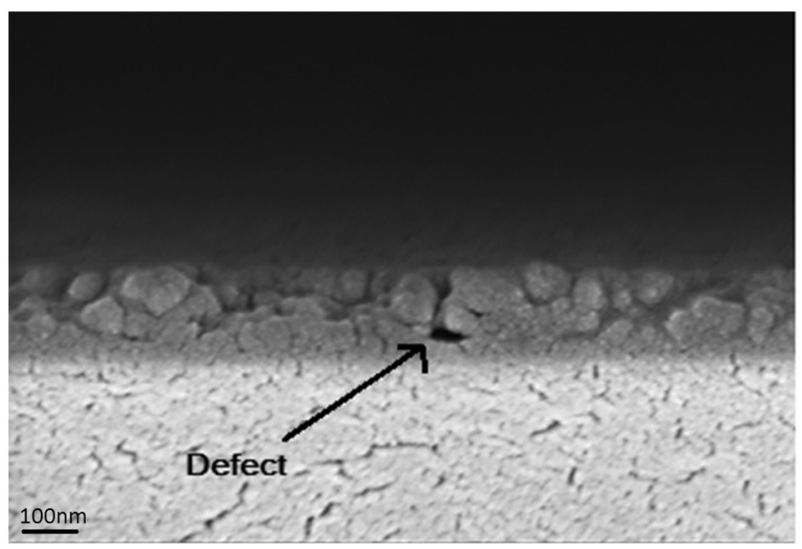

Fig. 5. A higher magnification image of an ARC cross section, showing a labelled defect where the coating is susceptible to water damage. 


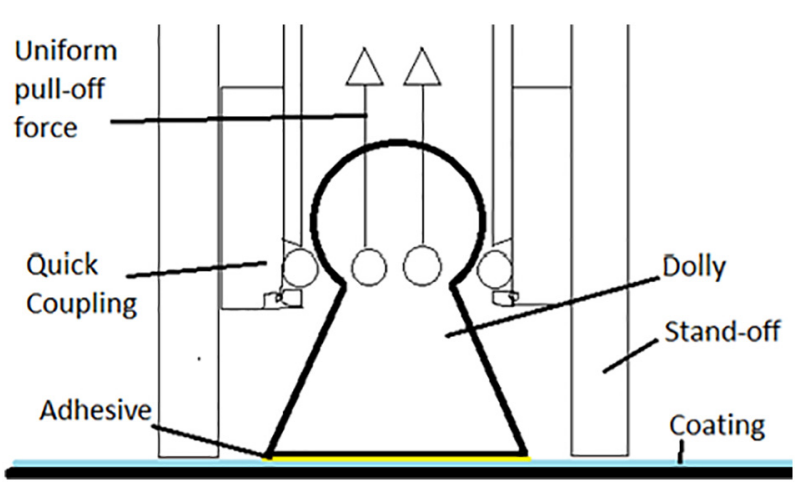

Fig. 6. A schematic diagram of a dolly fixed to the coating surface, the dolly, stand-off, coupling, and uniform pull-off force lines are all labelled.

\subsubsection{Pull test}

Pull tests were carried out in accordance with standards ISO 4624 and ASTM D4541 [24,25]. Aluminum dollies were fixed to the surface of the coating with an ethyl-2-cyanoacrylate based adhesive and then loaded into a Positest Adhesion tester. The dollies were then left to set. The Positest instrument then applied a uniform and increasing force to remove the dolly from the substrate, and the load is increased at a steady rate until the coating fails or the substrate breaks. A stand-off is used to keep the substrate still while the pull-off force is applied. A schematic diagram of the Positest is shown in Fig. 6.

Pull tests performed on the ARC were carried out using a dolly size of $20 \mathrm{~mm}$, with the standard ethyl-2-cyanoacrylate based adhesive. The dollies were sanded with 120 grit sandpaper and were glued 6 days prior to testing. The dollies were pulled at a rate of $0.7 \mathrm{MPa} / \mathrm{s}$. The coating withstood a maximum load of $4.92 \mathrm{MPa}$ before the glass substrate failed. Fig. 7 shows the glass substrate cracked and still partially stuck to the dolly $(\sim 45 \%)$. The glue is on the remaining surface of the dolly, and was removed from the surface of the coating. The coating was still intact across the entire surface of the glass, providing evidence that the sol-gel ARC has good adhesion.

\subsubsection{Cross-hatch test}

In the standard test, a pattern consisting of 6 parallel lines is created by scratching the coating using a round, 6-bladed, steel cutting knife manufactured by Dyne Technology Inc. (model number: CC1000). Then, 6 parallel lines are scratched, intercepting the initial lines at $90^{\circ}$ to create a cross-hatch pattern. The ARC displayed no visible damage after the tape or cross-hatch test. The ARC therefore has a score of 0 according to ISO 9211-4 [10], indicating excellent adhesion.

\subsection{High temperature stability}

The ARC has a complex structure with internal cavities. ARC samples were heated at $100{ }^{\circ} \mathrm{C}$ intervals up to $600{ }^{\circ} \mathrm{C}$. Before heat treatment, the surface of the ARC is almost featureless. After heat treatment, the optical properties of the coating are affected. Fig. 8(a) shows that damage begins to occur in the coating at above $100{ }^{\circ} \mathrm{C}$ heat treatment, and Fig. 8(b) shows severe damage is established at $200^{\circ} \mathrm{C}$.

Across the $350 \mathrm{~nm}$ to $850 \mathrm{~nm}$ wavelength range, the WAR of the samples had decreased from $2.6 \%$ to $2.28 \%$ after exposure to $400{ }^{\circ} \mathrm{C}$, and to $2.02 \%$ after exposure to $500{ }^{\circ} \mathrm{C}$. In Fig. 9 it can be seen that the cavities within the ARC are larger after exposure to $700{ }^{\circ} \mathrm{C}$ causing the appearance of blurry circles on the ARC surface. The WAR of the sample had increased to $3.2 \%$.

\subsection{Stability against thermal cycling}

Samples of the ARC were exposed to thermal cycling in accordance with IEC 61215. The samples were loaded into a Vötschtechnik VCS $7430-4$ environmental chamber and cycled between $-40{ }^{\circ} \mathrm{C}$ and $85^{\circ} \mathrm{C}$, with a minimum dwell time of $10 \mathrm{~min}$ at each temperature. As shown in Fig. 10, thermal cycling had a positive effect on the WAR of the samples. However, the change in WAR suggests the ARC is no longer as it was deposited and therefore the mechanical properties of the ARC may have been compromised. This result agrees with the functional resistance to remarkably high temperatures demonstrated by the ARC in Section 4.2 .

Considering the WAR before and after the test, it can be concluded that the effect of thermal cycling was a reduction in WAR, indicating structural changes and possible damage to the coating.

\subsection{Resistance to temperature and humidity (damp heat test)}

In accordance with IEC 61215, 2 samples of the ARC were loaded into an environmental chamber (Sanyo Gallenkamp HCC065) and held at $85{ }^{\circ} \mathrm{C}$ and $85 \%$ relative humidity ( $\mathrm{RH}$ ) for a total of $1000 \mathrm{~h}$. The reflectance of the samples was measured using a spectrophotometer at the beginning, on completion of the $1000 \mathrm{~h}$ test, and also at the mid-way point $(500 \mathrm{~h})$. Table 2 shows the effect of damp heat (DH) exposure on the reflectance of two ARC samples. Before each measurement the samples were cleaned in a 50-50 IPA and DI water mix, to isolate the effect of the DH test.

After $500 \mathrm{~h}$ of damp heat, the change in WAR was negligible. A slight reduction in WAR in sample 2 is most likely caused by a change in the coating porosity percentage or the coating thinning after prolonged heat exposure. After $1000 \mathrm{~h}$, the WAR of the samples 1 and 2 had increased by $0.94 \%$ and $0.62 \%$ respectively indicating the coating is susceptible to damage from exposure to damp heat. This would occur in

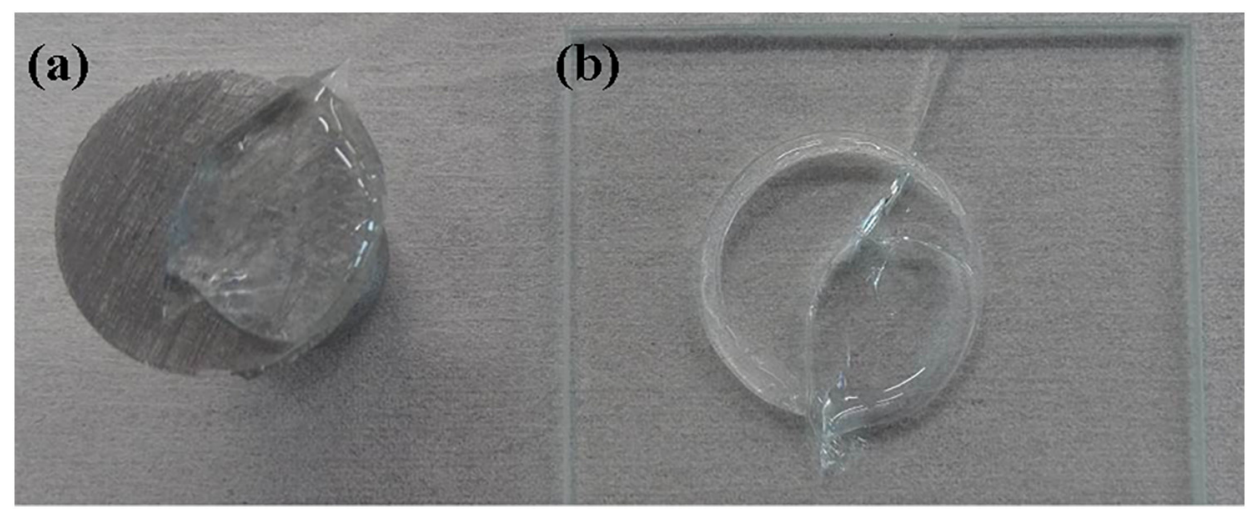

Fig. 7. (a) The base of a dolly with glass adhered to the surface, revealing no coating delamination. (b) A fractured sample of the ARC on glass after a pull test. The coating remained undamaged. Image courtesy of TWI. 


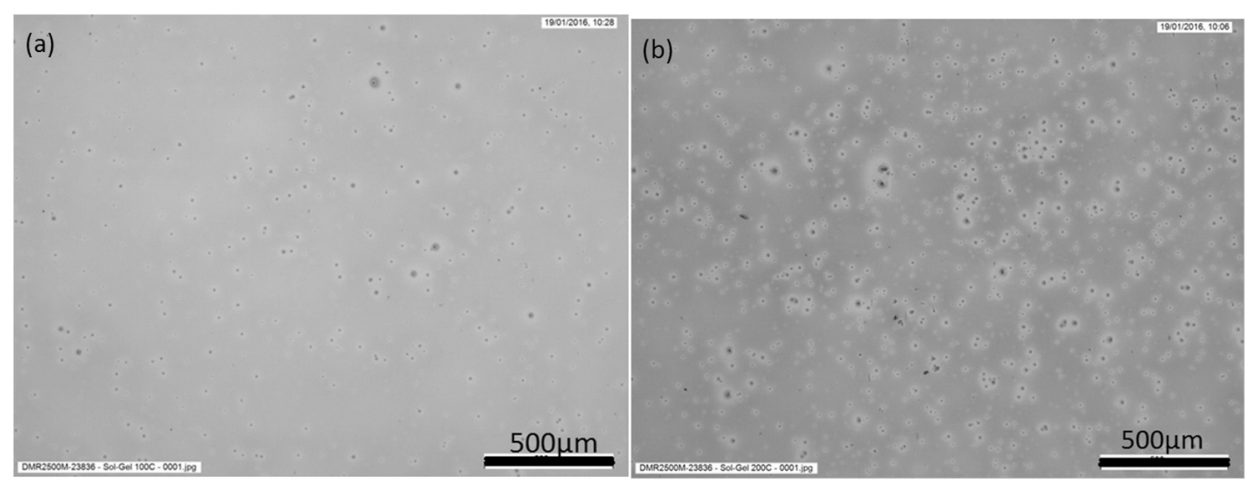

Fig. 8. (a) The surface of an ARC sample after heat treatment at $100^{\circ} \mathrm{C}$ for $30 \mathrm{~min}$. (b) The surface of an ARC sample after heat treatment at $200{ }^{\circ} \mathrm{C}$ for $30 \mathrm{~min}$, showing greater numbers of speckled features. (Image courtesy of TWI).

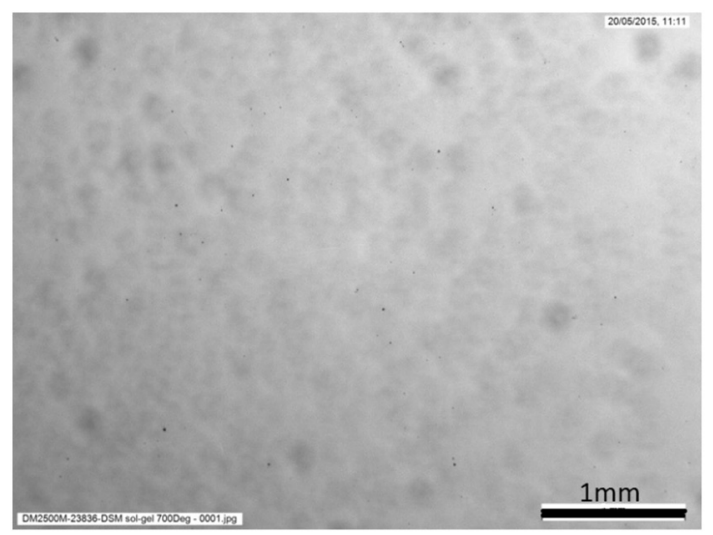

Fig. 9. The surface of an ARC sample after exposure to $700^{\circ} \mathrm{C}$ for $30 \mathrm{~min}$, circular features indicate the formation of larger voids beneath the coating surface. (Image courtesy of TWI).

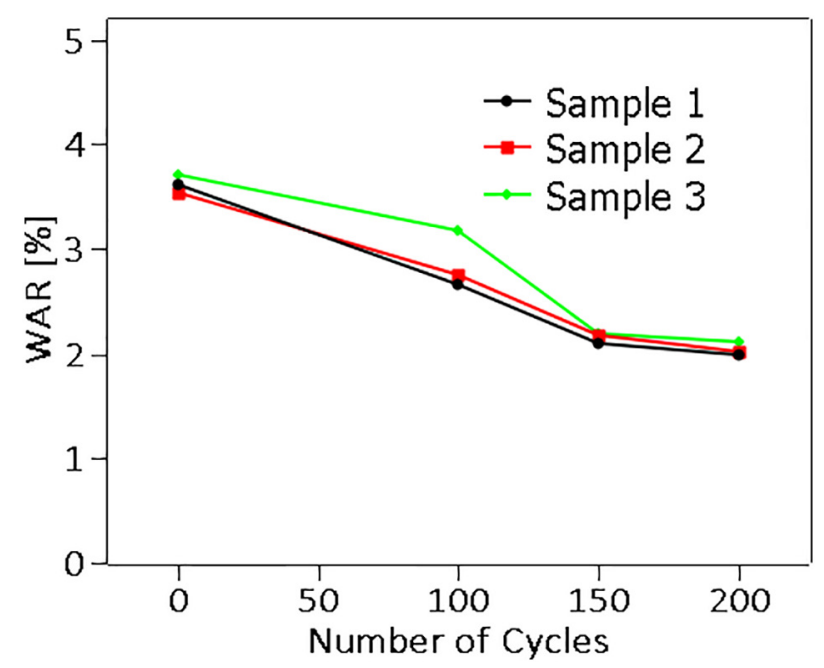

Fig. 10. The measured WAR of ARC samples cycled 0, 100, 150, and 200 times between $-40{ }^{\circ} \mathrm{C}$ and $85^{\circ} \mathrm{C}$ in a climatic chamber (a total time of $\sim 33 \mathrm{~h}$ ).

Table 2

Measured WAR of ARC samples after DH exposure.

\begin{tabular}{lcc}
\hline & Sample 1 & Sample 2 \\
\hline Initial & $2.25 \%$ & $2.35 \%$ \\
$500 \mathrm{~h}$ & $2.25 \%$ & $2.23 \%$ \\
$1000 \mathrm{~h}$ & $3.19 \%$ & $2.85 \%$ \\
\hline
\end{tabular}

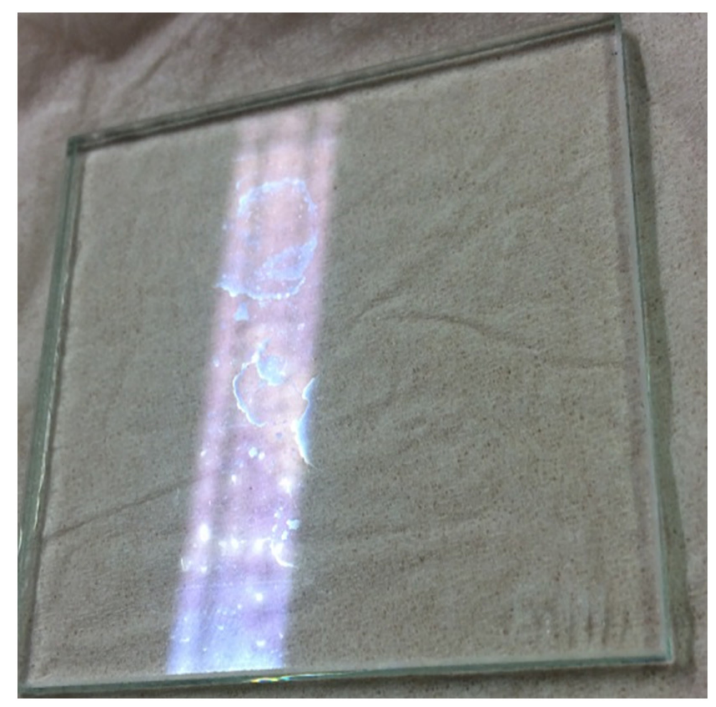

Fig. 11. Optical image of a sol gel coated glass surface showing signs of water damage after $1000 \mathrm{~h}$ of DH exposure. (Image courtesy of TWI).

hot and humid environments. The surfaces of the coatings appeared to have been affected by water exposure from the Damp Heat test. After $1000 \mathrm{~h}$, water marks are clearly visible as shown in Fig. 11.

\subsection{Water contact angle}

The water contact angle of the ARC was measured to be $9^{\circ}$ with a Kruss surface energy analyzer (DSA100). A water contact angle of $9^{\circ}$ indicates the coating is hydrophilic. The coating appears to absorb water. This is a concern for the long term performance of the ARC. If the coating absorbs water, the optical properties are diminished as the presence of water raises the refractive index of the coating. However, measuring this effect is difficult as the majority of water evaporates before and during reflectance measurements. A water contact angle measurement on the surface of an ARC sample is shown in Fig. 12.

\subsection{Water solubility test}

ARC samples were exposed to water solubility tests in accordance with ISO 9211-4 [10]. The least aggressive test is the immersion of the samples into DI water for up to $96 \mathrm{~h}$. After immersion, the samples were dried and the reflectance of the sample was measured. Initially the WAR of the ARC samples was reduced, suggesting a change in the coating structure. As shown in Fig. 13 WAR was initially reduced but then increased with exposure. An increase in WAR was measured after $24 \mathrm{~h}$ immersion and WAR continues to increase as the exposure time 


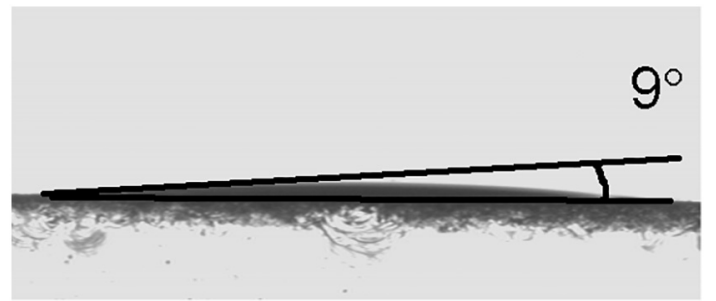

Fig. 12. A water drop on the surface of the ARC with a contact angle of $9^{\circ}$. (Image courtesy of TWI).

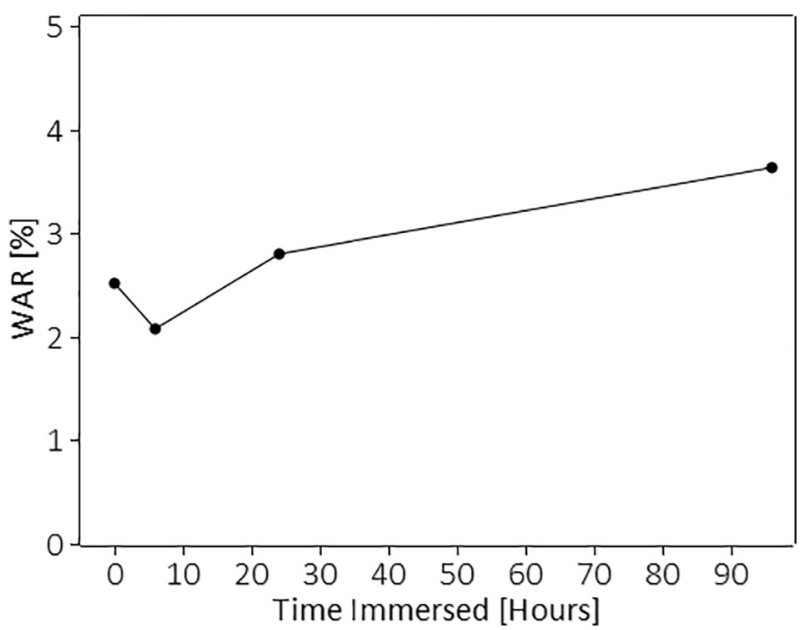

Fig. 13. The WAR of ARC samples after immersion in DI water for $0,6,24$, and $96 \mathrm{~h}$.

increases up to $96 \mathrm{~h}$. The WAR of the sample was measured after 6, 24, and $96 \mathrm{~h}$.

The coatings were then placed in boiling DI water for 5,10 , and 15 min periods. No physical degradation was observed after $15 \mathrm{~min}$. The WAR of the sample decreased after exposure to boiling water, as shown in Fig. 14. This is consistent with the findings of Sections 4.3 and 4.4, that heat improves WAR but damages the structure of the coating. The results shown in Fig. 13 suggest damage from water occurs on a timescale of hours.

In accordance with the final test in ISO 9211-4, the samples were placed in boiling DI water for $2 \mathrm{~min}$ and then immersed in room temperature DI water for $1 \mathrm{~min}$. This process was repeated 10 times and

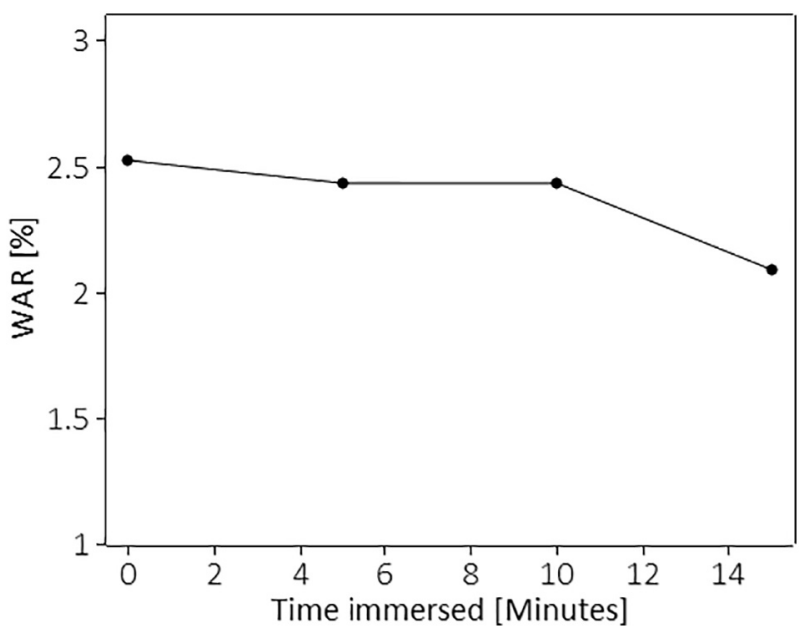

Fig. 14. The WAR of ARC samples after immersion in boiling DI water for 0,5 , 10 and $15 \mathrm{~min}$.

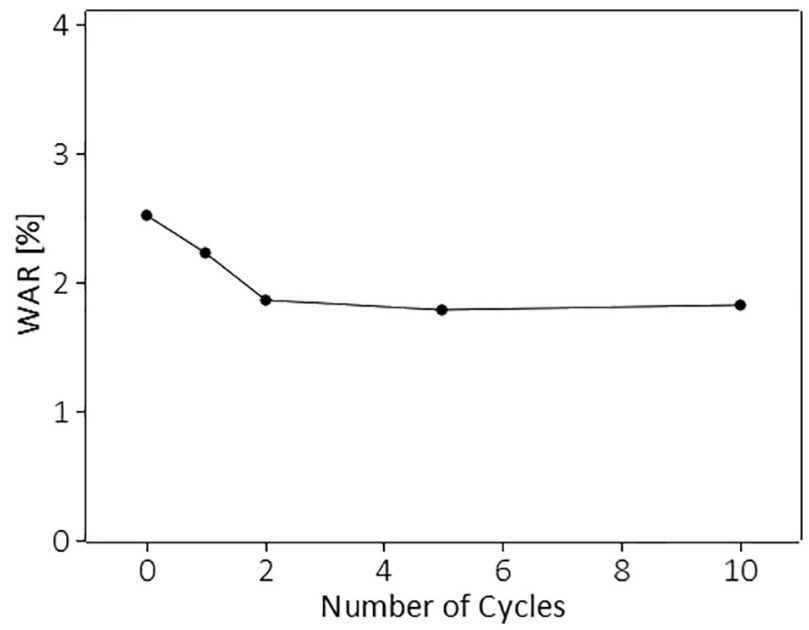

Fig. 15. The WAR of samples of ARC after $0,1,2,5$, and 10 cycles of $2 \mathrm{~min}$ in boiling DI water, followed by $1 \mathrm{~min}$ in room temperature DI water.

WAR measurements were taken after the 1st, 2nd, 5th, and 10th cycle. The samples displayed no visible degradation. The WAR was decreased due to heat damage after the first 2 cycles then remained relatively constant. The WAR of the samples is shown in Fig. 15.

\subsection{Exposure to acid}

As acid rain is common in many cities around the world, it is important to test the acid resistance of the sol-gel coating. ARC samples were submerged in dilute sulfuric acid with a $\mathrm{pH}$ of $\sim 3.5$. The type of acid and $\mathrm{pH}$ were selected to simulate acid rainwater [26]. The $\mathrm{pH}$ of the solution was measured using an Accumet AB150 pH meter. The WAR of the coating was measured after every $30 \mathrm{~min}$ of exposure. Fig. 16 shows the resulting WAR of the samples after exposure to acid for lengths of time.

Fig. 16 shows that exposure to acid over $30 \mathrm{~min}$ increases the WAR of the ARC by $\sim 1.2 \%$. This implies the coatings are vulnerable to degradation in an acidic environment.

\subsection{Scratch resistance}

Micro-indentation was used to measure the scratch resistance of the ARC [27]. A round end cone micro-indenter with a tip radius of $5 \mu \mathrm{m}$ was used. The micro-indenter was held at a force of $0.1 \mathrm{mN}$ at the

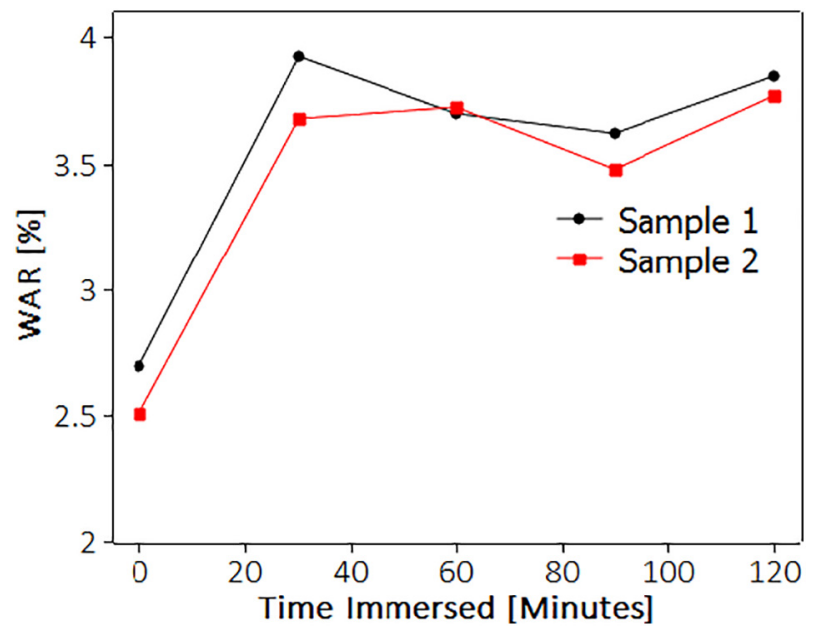

Fig. 16. The WAR of sol-gel samples after exposure to dilute sulfuric acid, simulating the effect of acid rain for $0,30,60,90$, and $120 \mathrm{~min}$. 


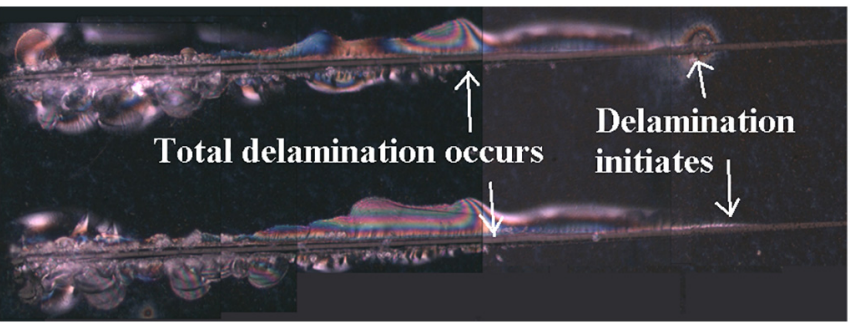

Fig. 17. Scratches in the surface of an ARC sample. The scratches were produced by pressing a micro-indenter into the surface of the coating and moving the sample as the load is increased. (Image courtesy of TWI).

surface of the sample, and then the load was increased at a rate of $1 \mathrm{mN}$ per $1 \mu \mathrm{m}$ as the micro-indenter travelled across the surface. The microindenter travelled $400 \mu \mathrm{m}$ and applied a maximum force of $400 \mathrm{mN}$ over the $5 \mu \mathrm{m}$ micro-indenter tip, $\sim 5 \mathrm{kPa}$ pressure.

An image of the resulting scratch from the micro-scratch test is shown in Fig. 17. The resting pressure of $0.1 \mathrm{mN}$ deformed the coating at $\sim 30 \mathrm{~nm}$. Fig. 17 shows that debris begins to appear next to the scratch very early, implying partial delamination at $\sim 20-40 \mathrm{mN}$. This point on the scratch is indicated in Fig. 17, labelled 'Delamination initiates'. At $\sim 180-200 \mathrm{mN}$, it appears the debris from the coating is much larger and shows interference effects, indicating the coating has begun to delaminate completely. In Fig. 18, this point is indicated by the label reading 'Total delamination occurs'. There are no cracks extending from the scratch, implying the damage the coating has sustained is localized.

\subsection{Abrasion resistance}

The cover glass of solar modules are cleaned on a regular basis to remove soiling. It is important to assess the possible damage to the coating caused by cleaning protocols. A felt pad abrasion test from BS EN 1096-2 [28], which uses a slow turning circular abrader, was adapted into a linear abrasion test. In the adapted test, a felt abrader with a surface area of $\sim 78.5 \mathrm{~mm}^{2}$ was applied to the surface of the ARC coating with a force of $10 \mathrm{~N}$. It was then passed across the surface 100 times, with a stroke length of $30 \mathrm{~mm}$ and a speed of 60 cycles per minute. This test was an attempt to simulate the effect of cleaning with a cloth or brush type appliance. This increased the WAR of the sample relatively by $33 \%$ from $2.75 \%$ to $3.65 \%$.

The CS-10 [29] abrader was pressed to the surface of ARC samples with a force of $5 \mathrm{~N}$ and $10 \mathrm{~N}$. The abrader was then repeatedly passed over the sample surface at 60 cycles per minute with a stroke length of

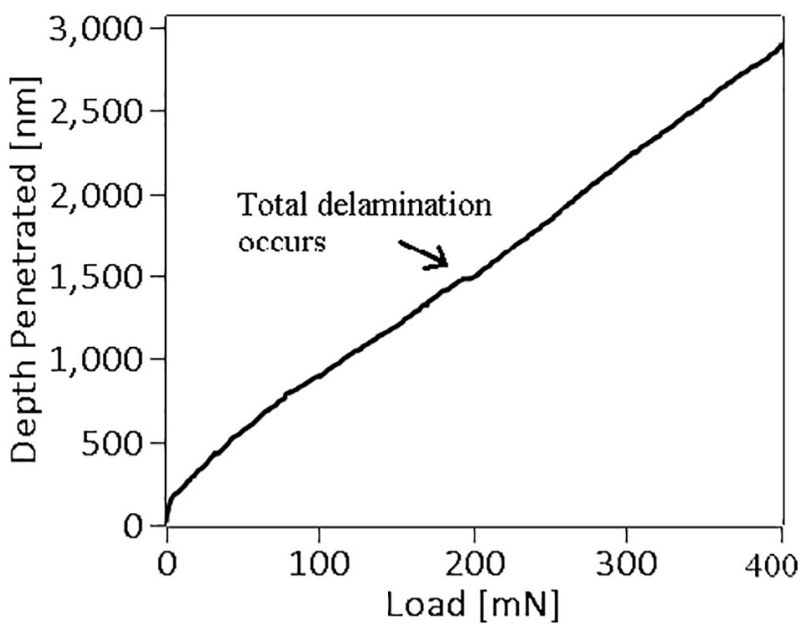

Fig. 18. Plot of the load applied to the micro-indenter against depth penetrated into the surface of the ARC sample.
$30 \mathrm{~mm}$. After 100 cycles at each force, the coatings were cleaned in an ultrasonic bath and the WAR was measured. This resulted in an absolute increase in WAR of $1.32 \%$ and $2.21 \%$ for $5 \mathrm{~N}$ and $10 \mathrm{~N}$ respectively. The increase in WAR is due to severe damage to the coating. This result suggests wear and tear is an issue for sol-gel ARCs and that care must be taken over the choice of cleaning materials and appliances for coated modules.

\section{Discussion}

Solar modules are installed with a typical 25 year warranty. It is important that the adhesion and durability of a coating applied to the cover glass is consistent with the warranty offered with solar modules. The coating is expected to withstand humidity, temperature cycles, and acid rain. The coating must also be scratch resistant to prevent damage during cleaning and maintenance. The performance of a single-layer, sol-gel ARC currently used on solar cover glass was evaluated. The coating proved to be an optically effective AR, resulting in a 69 -to $74 \%$ reduction in reflection losses when a solar irradiance weighted average was used depending on wavelength range used by the solar technology. Considering the cost and ease of application of simple porous silica coatings, this is an impressive reduction in reflection losses.

The adhesion of the ARC has been tested using standard IEC test methods. The pull test (ISO 4624) did not remove the ARC from the substrate. The highest recorded pull strength that failed to delaminate the coating was $4.92 \mathrm{MPa}$. The substrate shattered in every pull test and the coating was intact. After the coatings had undergone the cross-hatch test (ISO 9211-4), minimal delamination from the application and removal of tape was observed. The basic adhesion of the sol gel coatings is excellent.

The reflectance of the coating was observed to change with exposure to high temperatures with severe damage occurring above $200{ }^{\circ} \mathrm{C}$. Optical microscopy revealed changes to the coating microstructure and the formation of spherical features. Similar behavior was observed during thermal cycling tests. Although, the reflectance actually improves, the changes induced in the coating microstructure are likely to affect abrasion resistance. Temperatures above $200^{\circ} \mathrm{C}$ are unlikely to be experienced in the field or in the manufacturing process for crystalline silicon or CIGS solar modules. Cover glass pre-coated with a sol-gel ARC would not be suitable for use during thin film CdTe manufacturing in which the superstrate is exposed to temperatures above $500{ }^{\circ} \mathrm{C}$. However, the coating could be applied to the completed thin film CdTe module at room temperature.

The sol gel coating is hydrophilic with a water contact angle below $10^{\circ}$. This encourages the spread of water across the coated surface and ingress into defects. Immersion of the coating into de-ionised water caused changes to the reflectivity due to changes to the refractive index. The change to the refractive index is likely caused by water ingress into the coating cavities. The degradation observed in the damp heat test may be caused by this same mechanism. This is concerning because the damp heat test simulates the conditions found in hot and humid climates. The sensitivity of the coatings observed to acid attack would accentuate the degradation in polluted environments. The vulnerability of this type of coating to humidity has been reported in module field testing.in humid conditions.

The micro-indentation scratch test and the felt pad abrasion tests show that the coatings are relatively easily damaged and this damage affects the optical performance. Soiling is a serious issue for solar modules and the coatings are exposed to regular cleaning cycles. These tests indicate that great care must be taken over the type of cleaning materials and methods involved to avoid continuous damage to the coatings.

In summary, the present study provides an interesting insight into the performance and durability of single layer sol gel anti-reflection coatings when applied to a solar cover glass. The optical performance of the coatings is impressive. However, the IEC solar module tests indicate 
that coating degradation is likely to occur in humid climate conditions and also in areas with high levels of air pollution causing rainwater to be acidic. In addition, the coatings are vulnerable to the type of abrasion that could occur if aggressive cleaning methods are employed. It is important to stress that improvements to the coating technology is occurring continuously and that individual commercial coatings should be tested independently. Nevertheless, this study indicates the laboratory tests likely to reveal coating degradation in the field.

\section{Acknowledgements}

The authors are grateful to UKERC for funding this work through the EPSRC Supergen SuperSolar Hub (EP/J017361/1 and JM014797/ 1). One of the authors (GW) is grateful to NSIRC Ltd. for supporting a CASE studentship.

\section{References}

[1] IEC, Terrestrial Photovoltaic (PV) Modules - Design Qualification and Type Approval, IEC 61215, 2016.

[2] Z.Q. Guo, Y. Liu, M.Y. Tang, J.H. Wang, X.P. Su, Super-durable closed-surface antireflection thin film by silica nanocomposites, Sol. Energy Mater. Sol. Cells 170 (November) (2017) 143-148 (2016).

[3] X. Wang, J. Shen, Sol-gel derived durable antireflective coating for solar glass, J. Sol-Gel Sci. Technol. 53 (2) (2010) 322-327.

[4] G.I. Cooper, G.a. Cox, The aqueous corrosion of potash-lime-silica glass in the range 10-250 ㄷ, Appl. Geochem. 11 (4) (1996) 511-521.

[5] M. Vilarigues, R.C. da Silva, Characterization of potash-glass corrosion in aqueous solution by ion beam and IR spectroscopy, J. Non-Cryst. Solids 352 (50-51) (2006) 5368-5375.

[6] G.S. Vicente, R. Bayón, A. Morales, Effect of additives on the durability and properties of antireflective films for solar glass covers, J. Sol. Energy Eng. 130 (1) (2008) 011007.

[7] C.H. Chen, S.Y. Li, A.S.T. Chiang, A.T. Wu, Y.S. Sun, Scratch-resistant zeolite antireflective coating on glass for solar applications, Sol. Energy Mater. Sol. Cells 95 (7) (2011) 1694-1700.

[8] G. Womack, P.M. Kaminski, J.M. Walls, High temperature stability of broadband anti-reflection coatings on soda lime glass for solar modules, 42nd IEEE Photovoltaic Specialist Conference, 2015.

[9] C.R. Osterwald, T.J. McMahon, History of accelerated and wualification testing of terrestrial photovoltaic modules: a literature review, Prog. Photovolt. Res. Appl. 17
(2008) 11-33.

[10] ISO, "Optics and Photonics - Optical Coatings, Part 4: Specific Test Methods," ISO 9211-4:2012, (2012).

[11] A. Wojdyła, A. Taylor, G. Durand, I.W. Boyd, New assessment criteria for durability evaluation of highly repellent surfaces, Wear 390-391 (May) (2017) 49-60.

[12] P.M. Kaminski, F. Lisco, J.M. Walls, Multilayer broadband antireflective coatings for more efficient thin film CdTe solar cells, IEEE J. Photovoltaics 4 (1) (Jan. 2014) $452-456$.

[13] G. Womack, P.M. Kaminski, A. Abbas, K. Isbilir, R. Gottschalg, J.M. Walls, Performance and durability of broadband antireflection coatings for thin film CdTe solar cells, J. Vac. Sci. Technol. A 35 (2) (2017) 1-11.

[14] A.E. Conrady, Applied Optics and Optical Design Part One, 586 Oxford University Press, Oxford UK, 1929.

[15] S. Cai, Y. Zhang, H. Zhang, H. Yan, H. Lv, B. Jiang, Sol-gel preparation of hydrophobic silica antireflective coatings with low refractive index by base/acid two-step catalysis, ACS Appl. Mater. Interfaces 6 (14) (2014) 11470-11475.

[16] C.J. Brinker, G.W. Scherer, Sol-Gel Sciencea, 517 Academic Press, New York, 1990.

[17] J. Deubener, G. Helsch, A. Moiseev, H. Bornhoft, Glasses for solar energy conversion systems, J. Eur. Ceram. Soc. 29 (7) (2009) 1203-1210.

[18] M. Faustini, B. Louis, P. a Albouy, M. Kuemmel, D. Grosso, Preparation of sol - gel films by dip-coating in extreme conditions, J. Phys. Chem. C 114 (17) (2010) 7637-7645.

[19] P. Meredith, M. Harvey, "Silica and Silica-like Films and Method of Production," EP 1734016, (2006).

[20] J.C. Thies, E. Currie, G.J.W. Meijers, K. Gan, "Method of Preparing Nano-structured Surface Coatings and Coated Articles," US 7892606, (2011).

[21] P. Buskens, M. Burghoorn, M.C.D. Mourad, Z. Vroon, Antireflective coatings for glass and transparent polymers, Langmuir 32 (27) (2016) 6781-6793.

[22] J.C. Thies, E. Currie, G.J.W. Meijers, "Preparation of a Mechanically Durable Single Layer Coating With Anti-reflective Properties," US 7655298 B2, (2010).

[23] P. Löbmann, Antireflective coatings by sol-gel processing: commercial products and future perspectives, J. Sol-Gel Sci. Technol. 83 (2) (2017) 291-295.

[24] ISO, "Paints and Varnishes - Pull-off Test for Adhesion," ISO 4624, (2002).

[25] ASTM, "Standard Test Method for Pull-Off Strength of Coatings Using Portable Adhesion Testers," ASTM D4541, (2002).

[26] ASTM, "Standard Test Method for Accelerated Acid Etch Weathering of Automotive Clearcoats Using a Xenon-Arc Exposure Device," ASTM D7356/D735, (2006).

[27] R.H. Kim, H.J. Kim, I. Bae, S.K. Hwang, D.B. Velusamy, S.M. Cho, K. Takaishi, T. Muto, D. Hashizume, M. Uchiyama, P. André, F. Mathevet, B. Heinrich, T. Aoyama, D. Kim, H. Lee, J. Ribierre, C. Park, Non-volatile organic memory with sub-millimetre bending radius, Nat. Commun. 5 (3583) (2014).

[28] BSI, "Glass in Building. Coated Glass. Requirements and Test Methods for Class A, B and S Coatings," Bs En 1096-2:2012, (2002).

[29] ASTM, "Standard Test Method for Resistance of Transparent Plastics to Surface Abrasion," ASTM D1044-13, (2013). 